\title{
Business Undertaken Method and Distribution Model of E-commerce Oriented Integrated Logistics Platform
}

\author{
Guoping Chenga ${ }^{a}$ Wei Xun ${ }^{b}$ \\ School of Management, Wuhan University of Technology, Wuhan 430070, China \\ aGuopingcheng@tom.com, btan@nbl56.com
}

Keywords: e-commerce, integrated logistics platform, distribution model.

\begin{abstract}
E-commerce oriented integrated logistics platform is based on advanced Internet technology, which can establish open, transparent, shared data application platform. In order to reduce logistics cost and provide high-quality logistics service for e-commerce enterprises, it can integrate various social logistics resources and make an alliance with all kinds of logistics enterprises. In this paper, we study the business undertaken methods and distribution model of integrated logistics platform faced e-commerce. The research results can promote better cooperation between ecommerce enterprises and logistics enterprises.
\end{abstract}

\section{Introduction}

In recent years, e-commerce has developed rapidly in China, but the logistics cost is increasing year by year. E-commerce enterprises and logistics enterprises are both gradually aware of that modern logistics plays an important role in reducing cost, improving efficiency and enhancing competitiveness. E-commerce oriented integrated logistics platform can help e-commerce enterprises chose the right logistics enterprise in consideration of price and route. At present, the distribution timeliness in China is poor. Logistics information construction can enable logistics enterprises and consumers to share logistics information and help to improve logistics services level[1].Although most logistics enterprises are aware of the importance of logistics informatization, the funds, manpower and other inputs is insufficient. Moreover, it should build a comprehensive logistics platform to achieve data sharing and find the best distribution path from the perspective of whole industry. Therefore, the information construction is the most important in the development of the logistics industry. Only the logistics informatization is achieved, the systematization and network of logistics is about to achieve[2].Integrated logistics platform has many functions, such as warehousing management, order management, transportation management and so on. It can provide whole course service with the integration of information flow and capital flow [3].

\section{The Mode of E-Commerce Oriented Integrated Logistics Platform}

The integrated logistics platform for e-commerce is based on e-commerce platform, through the participation of logistics demand side (e-commerce enterprises) and logistics providers (third party logistics enterprises), it can release information in the platform. Then the system program will select the optimum plan, which can bring the two sides of value-added services.

The mode of e-commerce oriented integrated logistics platform is shown below, where the dotted line represents the direction of information transmission and the solid line represents the physical flow. When the customers have placed orders in all the e-commerce platforms, the demand information will be passed through the information system to the integrated e-commerce platform. Then, the platform contact with cooperative express companies and select the appropriate logistics providers to provide logistics service in the consideration of existing evaluation system. 


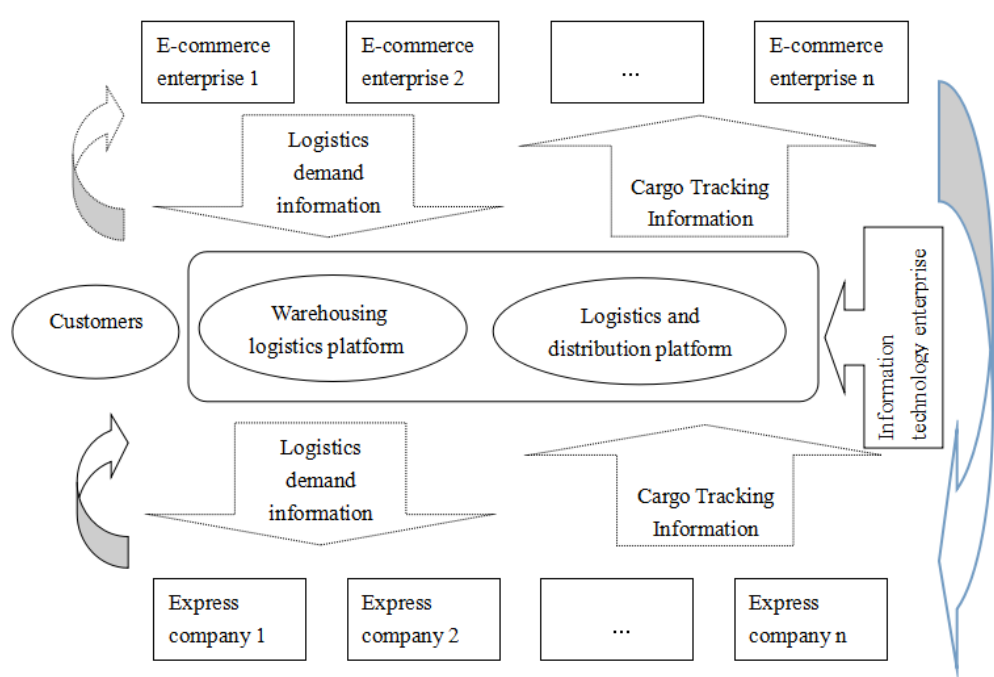

Fig.1 The mode of e-commerce oriented integrated logistics platform

\section{Business Undertaken Method of E-Commerce Oriented Integrated Logistics Platform}

The integrated logistics platform for e-commerce can undertake business mainly by modular method. The main participants in the integrated logistics platform are logistics enterprises and clients who need logistics service, so the business will be different because of different needs. For example, some clients need specialized warehouse leasing. Some clients need logistics and distribution service and others may need integrated logistics services. Classify modules according to different business needs, and then fractionize processing system of different businesses. The whole business undertaken process could be divided into three steps: comprehensive information input - analysis - business module classification. In brief, it is a process from centralization to separation.

\section{Business Distribution Model Overview}

On integrated logistics platform, each e-commerce enterprise has a lot of orders every day, and these orders are conducted to integrated logistics information platform to be distributed. The logistics business distribution diagram is as follows:

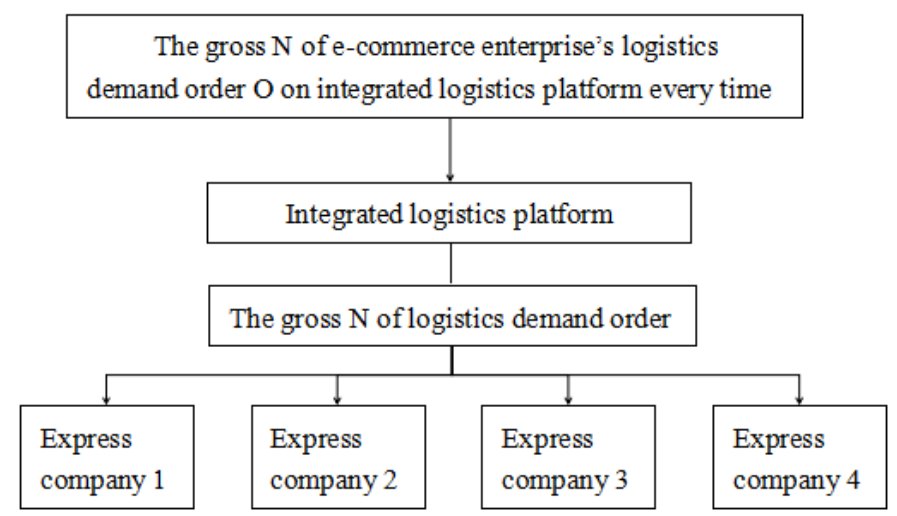

Fig. 2 The presentation of business order allocation

Business order allocation model on integrated logistics platform is a two-stage order allocation model. The first stage is to select from a strategic cooperative enterprises that meet the requirements of the order delivery courier company, the second level is on this basis, when a time under paragraph the total number of orders for order allocation, and found to meet all the conditions to minimize the cost of the combination. Screening criteria for courier companies in the first level has been mentioned in the previous section, that is according to customer requirements for timeliness of logistics services and product attributes to choose the appropriate logistics courier companies. So the first choice is the significance level required by the order to distinguish the courier company's logistics capabilities. 
Compared to the second stage it is more straight forward understanding of scientific rationality entire logistics solutions. The second stage is specific optimization model, namely, by allocation and distributing logistics enterprises which meet the ability requirement; people pursue the lowest cost distribution portfolio, which is the core of the optimization model.

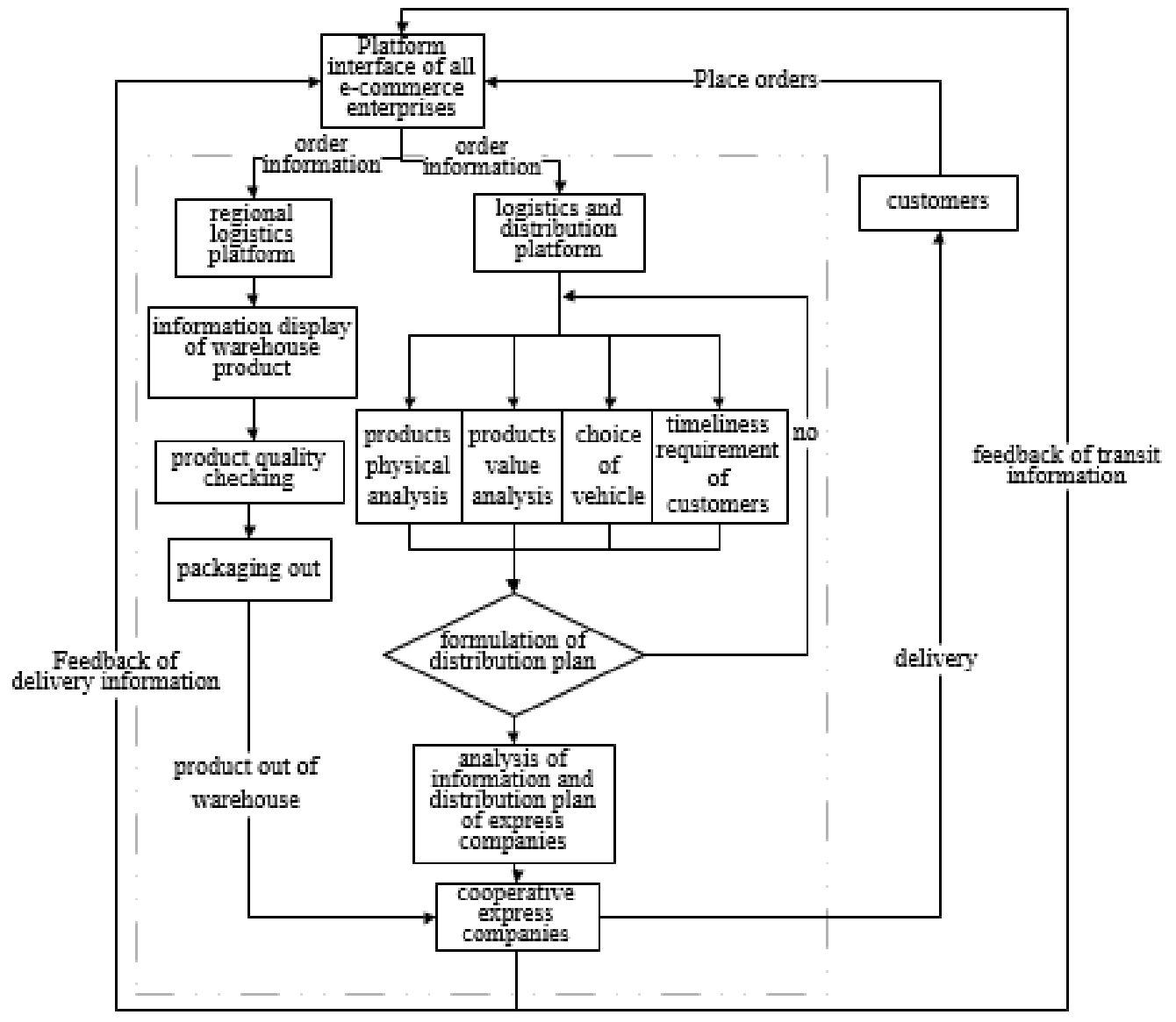

Fig.3 Flow chart of business orders undertaken and distribution

\section{Flow Chart of Business Orders Undertaken and Distribution}

The flow chart of business orders undertaken and distribution is seen as follow:

Information input. The first step of business undertaken and distribution is customers' transaction interface can display order information. That is to say, the information pass to the information port of the integrated logistics platform through the operation interfaces of the e-commerce enterprises, including the regional storage platform and logistics and distribution platform.

Products out of the warehouse. The contents of the order information can determine the terminal location of the logistics, and the function of the regional logistics platform is to choose the warehouse nearest to the logistics terminal location to pick up products according to the contents of the order. When the products leave the shelf and out of the warehouse, the storage platform will input all the information including quality inspection results, packaging bar code and final classification through information management function of the platform.

Choosing the right express company and in-transit tracking. The regional logistics platform is connected with the information system of the logistics distribution platform. When the warehouses of the products are determined, all the logistics management and decision-making activities of the products, from the warehouse to customers, are completed by the logistics distribution platform. The main function of the logistics distribution platform is to formulate the optimal distribution plan to meet the needs of customers, including the choice of modes of transportation, transportation routes, means of transport and express companies. 
After determining the warehouse and distribution destination, the platform will chose fast, safe and quality secured transport mode according to the interval distance, the physical properties and value of goods. Customers mainly take the time, cost, safety and convenience in to account. The main choice of transport means are is air express, high-speed rail and car.

Logistics distribution platform contains management information system and logistics service evaluation system of express companies. With the choice of distribution mode, the platform can find eligible express company. Then, it will distribute orders according to contracts of cooperation express companies on the platform.

Every business process of regional warehousing logistics platform and distribution platform is linked with information systems of all e-commerce enterprises. So, the people who need logistics services can know the whole logistics process clearly at any time. Besides, customers can search intransit product information conveniently.

\section{Summary}

China's logistics industry is developing rapidly. Many enterprises have the logistics capacity, but the business volume is not enough. So, the logistics assets are surplus to requirements. Integrated logistics platform can optimize logistics resource and at the same time it not only provide customers with high-quality logistics services but also bring the logistics service providers corporate profits. Therefore research on business undertaken method and distribution model of e-commerce oriented integrated logistics platform is significant.

\section{References}

[1]. Kai Jiang: Study on the Optimazition of Logistics Platform of XX E-Business Co., Ltd(Master, Dalian Maritime University,China2014).p.2-18

[2]. Haiyuan Huang. Research and Development on Warehousing Logistics Business Logical and Trading System for Integrated Logistics Information Platform (Master, Guangxi University, China2015). p.15-23

[3]. Baoshan Fu. Research and Implementation of Enterprise Logistics Platform System(Master, University of Electronic Science and Technology of China,China2010).p.23-31 